Original Research Article

\title{
A study of prevalence of metabolic syndrome in patients with type 2 diabetes mellitus in a tertiary care referral hospital in West Bengal
}

\author{
Tamoghna Maiti ${ }^{1}$, Sonai Mandal ${ }^{1}$, Ratul Banerjee ${ }^{1}$, Somenath Das $^{1}$, Amrita Panda $^{2}$
}

\begin{abstract}
${ }^{1}$ Department of Pharmacology, Bankura Sammilani Medical College, Bankura, West Bengal, India

${ }^{2}$ Anthropological Survey of India, Kolkata, West Bengal, India
\end{abstract}

Received: 17 July 2019

Revised: 20 August 2019

Accepted: 21 August 2019

*Correspondence to:

Dr. Sonai Mandal,

Email: mandal.sonai@

yahoo.co.in

Copyright: (C) the author(s), publisher and licensee Medip Academy. This is an openaccess article distributed under the terms of the Creative Commons Attribution NonCommercial License, which permits unrestricted noncommercial use, distribution, and reproduction in any medium, provided the original work is properly cited.

\begin{abstract}
Background: The terms "metabolic syndrome", "insulin resistance syndrome" and "syndrome $\mathrm{X}$ " are now used specifically to define a constellation of abnormalities that is associated with increased risk for the development of type 2 diabetes and atherosclerotic vascular disease. It is a state of chronic low grade inflammation with the profound systemic effects. Several organisations gave several criteria to diagnose it. Effective preventive approaches include lifestyle changes, primarily weight loss, diet, and exercise, the appropriate use of pharmacological agents to reduce the specific risk factors.

Methods: A cross-sectional study was done to evaluate the co-morbidity profile of patients, with metabolic syndrome and correlate clinical manifestations with specific components or metabolic syndrome, at the OPD of Bankura Sammilani Medical College and Hospitals, West Bengal. American Association of Clinical Endocrinologists criteria were chosen for diagnosis.

Results: 100 patients were recruited having type II diabetes mellitus. Most of the patients were male between 20-70 years and maximum was on oral hypoglycemic agent with app $40 \%$ patient was without any glycemic control. In comorbidities hypertension was highest, followed by coronary artery disease, hypothyroidism and cerebrovascular accident. Waist-hip ratio was highest in female. All of the patients were having some cardiac risk factor assessed by ECG, echocardiography and thread mill test.

Conclusions: The data demonstrates that metabolic syndrome is extremely common among diabetic patients. Frequency was much higher in women than men. Obesity is a key element in causing the metabolic syndrome and this factor was also more common in women.
\end{abstract}

Keywords: Metabolic syndrome, Type 2 diabetes, Cardiovascular risk

\section{INTRODUCTION}

The term "metabolic syndrome" dates back to at least the late $1950 \mathrm{~s}$, but came into common usage in the late $1970 \mathrm{~s}$ to describe various associations of risk factors with diabetes that had been noted as early' as the 1920s. ${ }^{1,2}$ In 1977 and 1978 Phillips developed the concept that risk factors for myocardial infarction concur to form a "constellation of abnormalities" (i.e. glucose intolerance, hyperinsulinemia, hyperlipidemia (hypercholesterolemia, hypertriglyceridemia) and hypertension that is associated not only with heart disease, but also with aging, obesity and other clinical states. ${ }^{3}$ He suggested there must be an underlying linking factor, the identification of which could lead to the prevention of cardiovascular disease. He hypothesized that this factor was sex hormones. ${ }^{3}$ In 1988 , Reaven proposed insulin resistance as the underlying factor and named the constellation of abnormalities as Syndrome X. Reaven did not include abdominal obesity. which has also been hypothesized as the underlying factor as part of the condition. ${ }^{4}$ The terms "metabolic syndrome" "insulin resistance syndrome" and "syndrome $\mathrm{X}^{\prime \prime}$ are now used specifically to define a constellation of abnormalities that is associated with increased risk for the development of type 2 diabetes and atherosclerotic vascular disease (e.g.. heart disease and stroke). Metabolic syndrome confers a 5-fold increase in the risk 
of type 2 diabetes mellitus (T2DM) and 2-fold the risk of developing cardiovascular disease (CVD) over the next 5 to 10 years. ${ }^{5}$ A version of metabolic syndrome has a WHO International Classification of Disease (ICD-9) code (277.7) which permits healthcare reimbursement. This shows that the term "metabolic syndrome" is institutionalized and a part of the medical vocabulary. It is considered as a first order risk factor for atherothrombotic complications. Its presence or absence should therefore be considered an indicator of long-term risk. $^{6}$ At least 3 organisations (National Cholesterol Education Program's Adult Treatment Panel III report, WHO and American Association of Clinical Endocrinologists (AACE) have recommended clinical criteria for the diagnosis of the metabolic syndrome. ${ }^{7}$ The criteria used are similar in many respects, but there are significant differences.

It is a state of chronic low grade inflammation with the profound systemic effects. Clinical identification and management of patients with the metabolic syndrome are important to begin efforts to adequately implement the treatments to reduce their risk of subsequent diseases. ${ }^{8}$ Effective preventive approaches include lifestyle changes, primarily weight loss, diet, and exercise, and the treatment comprises the appropriate use of pharmacological agents to reduce the specific risk factors. Pharmacological treatment should be considered for those whose risk factors are not adequately reduced with the preventive measures and lifestyle changes. ${ }^{9}$ A single agent is generally recommended and an average weight loss ranges greatly from $5 \%$ to $10 \%$ of initial weight. ${ }^{10}$ Appetite suppressants include phentermine derivatives and sibutramine. Statins are considered to be the most effective class of drugs for reducing the LDL-C concentrations due to their minimal drug-drug interactions and side effects. ${ }^{11}$ The guidelines recommend that the LDL-C goals should be set at less than $130 \mathrm{mg} / \mathrm{dl}$ with the option of targeting less than $100 \mathrm{mg} / \mathrm{dl}$ in the moderately high-risk individuals. Other condition like hypertension, insulin resistance and hypercoagulable test should be treated with angiotensin converting enzyme (ACE) inhibitor, aldosterone antagonist, diuretic and aspirin accordingly. ${ }^{12}$

Our objective was to measure the number of patient with type 2 diabetes fitted in the criteria for metabolic syndrome and increasing risk of cardiovascular disease. We have also seen if there is any gender variation.

\section{METHODS}

The study was done to evaluate the co-morbidity profile of patients with metabolic syndrome and correlate clinical manifestations with specific components of metabolic syndrome, coming to the OPD of Bankura Sammilani Medical College and Hospitals, West Bengal from August 2018 to July 2019, for 18 months.
It was a cross-sectional study done after approval by the Ethics committee. When the patients attended the OPD, we filled up the case report form and asked for necessary reports to be done from the central pathology and biochemistry and imaging section. We included the patient, who met our inclusion and exclusion criteria. Then we have calculated the cardiovascular (CV) risk. For the entire time period the values of the different parameter of the case report forms were taken in a single time. No follow-up was done. Only the prevalence measured.

\section{Inclusion criteria}

Inclusion criteria were a known case of type 2 diabetes mellitus; patients of age between 20-70 years of both sex.

\section{Exclusion criteria}

Exclusion criteria were patients with gestational diabetes and a known case of type 1 diabetes mellitus.

We have used AACE clinical criteria for diagnosis of the metabolic syndrome.

Cut points for abnormality (AACE criteria):

- Overweight/obesity- BMI $\geq 25 \mathrm{~kg} / \mathrm{m}^{2}$.

- $\quad$ Elevated triglycerides $\geq 1.70 \mathrm{mmol} / \mathrm{l}$.

- Low HDL cholesterol men <1.04 mmol/l, women $<1.30 \mathrm{mmol} / \mathrm{l}$.

- $\quad$ Elevated blood pressure $\geq 130 / 85 \mathrm{~mm} \mathrm{Hg}$.

- 2-Hour post-glucose challenge $>7.8 \mathrm{mmol} / \mathrm{l}$.

- Fasting glucose- 6.1 to $6.9 \mathrm{mmol} / \mathrm{l}$.

- Other risk factor- Family history of type 2 diabetes, hypertension, CVD.

- Polycystic ovarian syndrome.

- Sedentary lifestyle.

- Advancing age.

- Ethnic groups having high risk for type 2 diabetes or CVD.

A detail statistical analysis was carried out at the end of the study. We have spread the data in the Excel sheet. We have used graph pad prism software version 5 for calculating mean and Standard deviation. We have used chi-square test and student $\mathrm{t}$ test for comparison for categorical and numerical data. We have also calculated different percentages by simple arithmetic method.

\section{RESULTS}

Total 100 patients were recruited in the time period of the study, who met our inclusion and exclusion criteria. They were confirmed case of type 2 diabetes mellitus. Among them 53 patients were male and 47 were female (Figure 1). All of them were in between 20 to 70 years, mean age being 47.45 year. In both the occasion $P$ value was insignificant $(\mathrm{p}>0.5)$. We have arranged the patient according to the anti-diabetic medication they were on. 
Maximum patient were on oral hypoglycemic agent (33\%), followed by oral hypoglycemic agent and insulin combination and only Insulin. $3 \%$ patient were on indigenous medication. Surprisingly $12 \%$ patients did not get any medication (Figure 2). About glycemic control, $48 \%$ patient had good control, $40 \%$ had poor control, $8 \%$ had no control and $4 \%$ patient did not monitor their blood glucose at all.

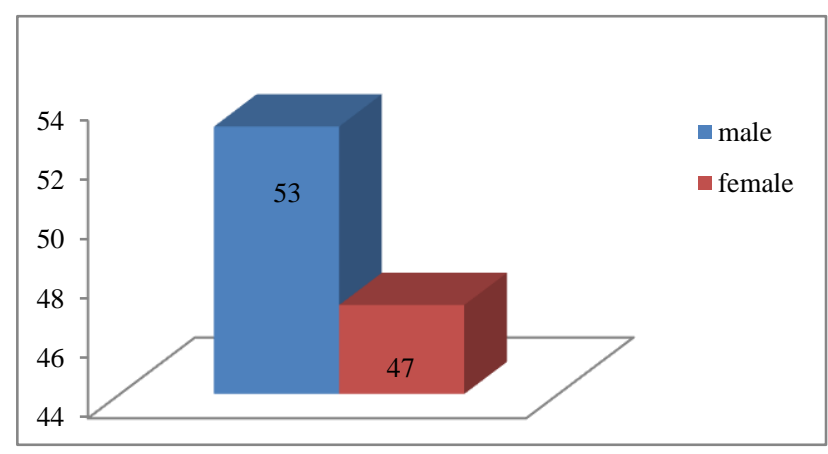

Figure 1: Gender distribution.

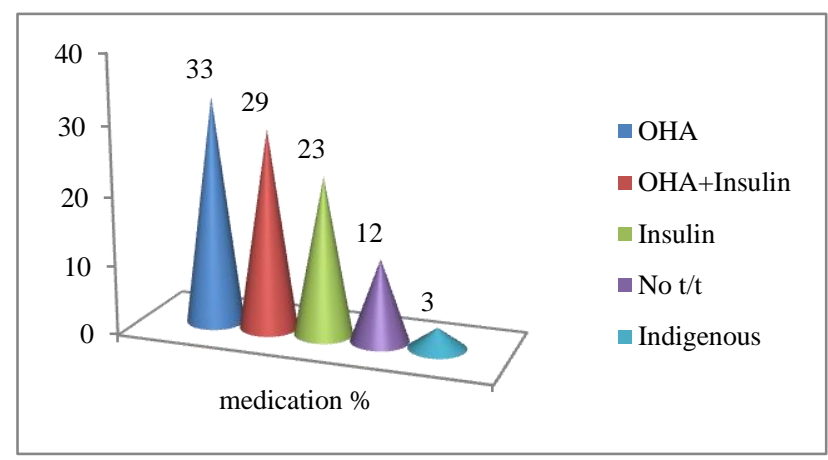

Figure 1: Anti-diabetic medication.

The patients were suffering from associated ailments, even more than one comorbid condition. Hypertension was highest, followed by coronary artery disease, hypothyroidism and CVA. Obstructive sleep apnoea, retinopathy and nephropathy was comprised a good number also (Figure 3). 11\% patients were smoker and $29 \%$ were alcoholic in the study population.

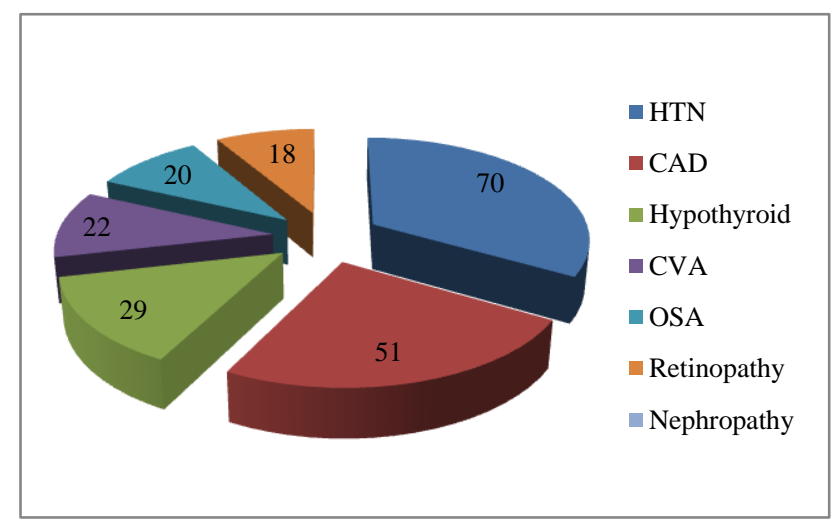

Figure 2: Comorbidity.
Mean waist/hip ratio of female was greater than male (1.06>1.07). Mean height and weight was more in case of male but BMI was more in case of female (Figure 4).

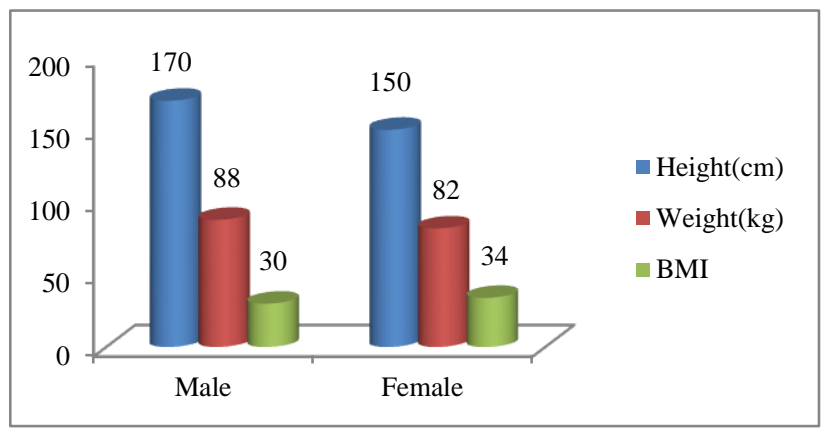

Figure 3: Weight, height, BMI.

Table 1: Lipid profile.

\begin{tabular}{|l|l|}
\hline Lipid profile & Mean \pm SD \\
\hline Total cholesterol & $243 \pm 39$ \\
\hline Triglyceride & $288 \pm 65$ \\
\hline LDL cholesterol & $198 \pm 45$ \\
\hline HDL cholesterol & $29 \pm 11$ \\
\hline
\end{tabular}

All of the patients had some cardiovascular risk as seen with biochemical, imaging relevant parameter, we saw that $49 \%$ patient had left ventricular hypertrophy (LVH) with strain pattern in ECG and $11 \%$ had T inversion. $44 \%$ patient has concentric $\mathrm{LVH}, 31 \%$ patient had mild LV diastolic dysfunction, and $28 \%$ patient had regional wall motion abnormality in Echocardiography. $51 \%$ patient had positive thread mill test for provocative ischemia. Mean value of lipid profile is depicted in Table 1.

In the present study, we found that family history of premature coronary artery disease (CAD) was also common in patients with metabolic syndrome. Whether this finding reflects deleterious co influence of faulty lifestyle patterns in these families or of genetic make-up or a combination of both was not apparent from the present study. Nonetheless, family history of premature CAD is also a recognized major risk factor for CAD.

\section{DISCUSSION}

There is currently debate as to whether metabolic syndrome increases the risk of adverse health outcomes beyond the risk associated with the individual component risk factors. ${ }^{13}$ The existing diagnostic criteria for metabolic syndrome arose from deliberations of panels of experts rather than from the results of prospective epidemiological studies or an evidence based process. ${ }^{14}$

The incidence of the metabolic syndrome is rising worldwide. This is partly due to a significant increase in the prevalence of obesity. The aetiology of the metabolic syndrome is multifactorial such as the high prevalence of excess body fat, abnormal body fat distribution, 
hypertriglyceridemia, and insulin resistance. These risk factors might begin at a young age and its high frequency has been consistently recorded in Asian populations irrespective of their geographic locations. ${ }^{15}$ Obesity related type 2 diabetes is also rapidly raising in prevalence, not only in west but also in Asians largely because of increased longevity and sedentary lifestyles. In this study, gender-specific prevalence rates of overweight and obesity were significantly higher among the female subjects, a pattern that agreed with both a similar study in Nigeria and the WHO report on obesity. ${ }^{16,17}$ Waist hip ratio was high in case of female. This gender pattern may be accounted for by the fact that men tend to deposit fat in the abdomen (upper body or android obesity) while women deposit fat more on the hips (lower body or gynaecoid obesity). These patterns of body fat deposition are thought to be influenced by sex hormones which not only influence the pattern of body fat distribution but also the burden of obesity in women. ${ }^{18}$ In our study we have also found similar result. Applying the AACE criteria for diagnosing the metabolic syndrome, a significantly high frequency was seen in women. ${ }^{19,20}$ But we found a little bit male preponderance, probably due to geographical variation and may be in rural area female are less health conscious and they attend OPD less than male. The prevalence of the various risk factors was also higher among individuals with metabolic syndrome. Further, in adults who have type 2 diabetes, the presence of metabolic syndrome is associated with a fivefold increase in $\mathrm{CV}$ risk independent of age, sex, smoking status and glycated haemoglobin (HbA1C). ${ }^{21}$ in our study also we have found that all the patients had increased risk of cardiovascular disease. Therefore, it is imperative that aggressive therapy is needed aimed at controlling dysglycemia, dyslipidemia and hypertension. A novel aspect of this study was the analysis of waist circumference thresholds in the presence or absence of two or more other metabolic syndrome risk factors. The results provide support for a valuable role for waist circumference in the clinical definition of metabolic syndrome: however, it is apparent that a high waist circumference value in the absence of additional risk factors may not indicate increased mortality risk. ${ }^{20}$

\section{CONCLUSION}

The data demonstrates that metabolic syndrome is extremely common among diabetic patients, making it a risk factor for the development of diabetic complications. Frequency was much higher in women than men. Obesity is a key element in causing the metabolic syndrome and this factor was also more common in women. And the patient with metabolic syndrome is surely of increased CV risk.

\section{ACKNOWLEDGEMENTS}

Authors would like to thank to Dr. Shyamal Kundu, H.O.D. Department of medicine, and Dr. S.M. Naser, H.O.D. Department of Pharmacology and also to
Associate Professor Dr. Ananya Mandal and Assistant Professor Dr. Tanmoy Gangopadhyay for their cooperation in present work and also grateful to all nonmedical staffs of Medicine OPD and Pharmacology Department of Bankura Sammilani Medical College for their help in present work. Authors are also thankful to all PGTs and other faculty of Pharmacology Department of the same institution.

\section{Funding: No funding sources}

Conflict of interest: None declared

Ethical approval: The study was approved by the Institutional Ethics Committee

\section{REFERENCES}

1. Joslin EP. The prevention of diabetes mellitus. JAMA. 1921;76:79-84.

2. Kylin E. Studies of the hypertension-hyperglycemiahyperuricemia syndrome (German). Zentralbl Inn Med. 1923;44:105-27.

3. Phillips GB. Relationship between serum sex hormones and glucose, insulin, and lipid abnormalities in men with myocardial infarction. Proc Nail Acad Sci USA. 1977;74:1729-33.

4. Reaven GM. Banting lecture 1988. Role of insulin resistance in human disease. Diabetes. 1988;37:1595607.

5. Alberti KGMM, Eckel RH, Grundy SM, Zimmet PZ, Cleeman JI, Donato KA, et al. Harmonizing the metabolic syndrome: a joint interim statement of the international diabetes federation task force on epidemiology and prevention; National heart, lung, and blood institute; American heart association; World heart federation; International atherosclerosis society; And international association for the study of obesity. Circulation. 2009;120(16):1640-5.

6. Kaur J. A comprehensive review on metabolic syndrome. Cardiol Res Pract. 2014;2014:943162.

7. Eckel RH, Grundy SM, Zimmet PZ. The metabolic syndrome. The Lancet. 2005;365(9468):1415-28.

8. Wong ND. Intensified screening and treatment of the metabolic syndrome for cardiovascular risk reduction. Preventive Cardiol. 2005;8(1):47-54

9. Deen D. Metabolic syndrome: time for action. The Am Family Physician. 2004;69(12):2875-87.

10. Wilson PWF, Grundy SM. The metabolic syndrome practical guide to origins and treatment: part I. Circulation. 2003;108(12):1422-4.

11. National Cholesterol Education Program (NCEP) Expert Panel on Detection, Evaluation, and Treatment of High Blood Cholesterol in Adults (Adult Treatment Panel III). Third Report of the National Cholesterol Education Program (NCEP) Expert Panel on Detection, Evaluation, and Treatment of High Blood Cholesterol in Adults (Adult treatment panel III) final report. Circulation. 2002;106(25):3143-421.

12. Eidelman RS, Hebert PR, Weisman SM, Hennekens $\mathrm{CH}$. An update on aspirin in the primary prevention 
of cardiovascular disease. Arch Internal Med. 2003;163(17):2006-10.

13. Wild S, Roglic G, Green A, Sicree R, King H. Global prevalence of diabetes: Estimates for the year 2000 and projections for 2030. Diabetes Care. 2004:27:1047-53.

14. Gupta R, Deedwania PC, Gupta A, Rastogi S, Panwar RB, Kothari K. Prevalence of metabolic syndrome in an Indian urban population. Int $\mathbf{J}$ Cardiol. 2004:97:257-61.

15. Hu G, Qiao Q, Tuomilehto J, Balkau B, BorchJohnsen K, Pyorala K. Prevalence of the metabolic syndrome and its relation to all-cause and cardiovascular mortality in nondiabetic European men and women. Arch Intern Med. 2004;164:106676.

16. Desalu OO, Salami AK, Oluboyo PO, Olarinoye JK. Prevalence and socio-demographic determinants of obesity among adults in an urban Nigerian population. Sahel Med J. 2008;11:61-4.

17. WHO Non-Communicable Disease Country Profiles. Available at: http://www.who.int/countries/nga/en/. Accessed on 10 November 2014.
18. Lovejoy JC. The influence of sex hormones on obesity across the female life span. J Womens Health. 1998;7:1247-56.

19. Bruno G, Merletti F, Biggeri A, Bargero G, Ferrero S, Runzo C, et al. Metabolic syndrome as a predictor of all-cause and cardiovascular mortality in type 2 diabetes: The Casale Monferrato study. Diabetes Care. 2004;27:2689-94.

20. Foucan L. Deloumeaux J, Donnet JP, Bangou J, Larifla Messerchmitt C, Salmi LR, Kangambega P. Metabolic syndrome components in Indian migrants with type 2 diabetes. A matched comparative study. Diabetes Metab. 2006;32:337-42.

21. A population-based study. Risk Factor and Life Expectancy Research Group. Am J Epidemiol. 1998;148:958-66.

Cite this article as: Maiti T, Mandal S, Banerjee R, Das S, Panda A. A study of prevalence of metabolic syndrome in patients with type 2 diabetes mellitus in a tertiary care referral hospital in West Bengal. Int $\mathbf{J}$ Basic Clin Pharmacol 2019;8:2262-6. 